\title{
Genotype, environment and the asymmetry phenotype. Dieldrin-resistance in Lucilia cuprina (the Australian sheep blowfly)
}

\author{
JOHN A. MCKENZIE* \& JANET L. YEN \\ Department of Genetics, University of Melbourne, Parkville, Victoria 3052, Australia
}

\begin{abstract}
Dieldrin-resistant $(R d l / R d l$ and $R d l /+)$ and susceptible $(+/+)$ phenotypes of Lucilia cuprina were scored for departures from bilateral symmetry for bristle characters after development at different temperatures, larval densities or concentrations of dieldrin. The asymmetry phenotype of resistant flies was dominant and independent of developmental temperature and larval density. The asymmetry of susceptibles increased for temperatures and larval densities above and below standard rearing conditions. A positive correlation was observed between asymmetry score and dieldrin concentration for all genotypes. The susceptible phenotype did not attain the asymmetry score of resistants in any environment. Resistant phenotypes showed an antisymmetric pattern in each environment; fluctuating asymmetry was observed for susceptibles. The relevance of the results of genetic and general or specific environmental stresses to estimates of developmental perturbation is discussed.
\end{abstract}

Keywords: asymmetry, blowfly, dieldrin resistance, Lucilia cuprina.

\section{Introduction}

Evolutionary developmental biology (Arthur, 1987; Atchley \& Hall, 1991; Hall, 1992; Kieser, 1993) allows the integration of developmental processes, fitness and adaptation by considering frameworks of developmental constraint (Maynard Smith et al., 1985) and departures from developmental stability (Zakharov \& Graham, 1992). Changes in symmetry of usually bilaterally symmetrical organisms are used to estimate developmental perturbation (Palmer \& Strobeck, 1986). There is, however, considerable debate about the relevance of particular patterns of asymmetry /fluctuating asymmetry, antisymmetry and directional asymmetry (Palmer \& Strobeck, 1986)) to this estimation and of the contribution of genetic and specific or general environmental influences to the patterns observed (Palmer \& Strobeck, 1986, 1992; Parsons, 1990; Graham, 1992; Graham et al., 1993a,b; McKenzie \& O'Farrell, 1993).

Departures from symmetry are potentially powerful tools in analysing questions of applied, developmental or evolutionary origin (Markow \& Ricker, 1991; Clarke et al., 1992; Møller \& Höglund, 1992; Thornhill, 1992; Zakharov \& Graham, 1992; Markow, 1994). Environmentally or genetically determined

\footnotetext{
*Correspondence.
}

changes to the normal developmental pathway may be accompanied by a physiological cost (Maynard Smith et al., 1985; Scharloo, 1991; Zakharov, 1992; Kieser, 1993) reflected by an increase in asymmetry of an individual or population (Markow, 1994). Interpretation of departures from symmetry is difficult when the genetic basis of the phenotypic change is ill-defined (Leary \& Allendorf, 1989; Parsons, 1990, 1992; Graham, 1992). The relative contribution of genetic and environmental influences to the phenotype has been examined in few systems (Markow, 1994). However, such a partitioning is necessary if the potential of the asymmetry phenotype in population analysis is to be fully realized.

In this context there are three major issues to resolve. First, are genetically based changes in asymmetry relevant to estimates of developmental stability (Palmer \& Strobeck, 1992; Parsons, 1992; Graham et al., 1993a; McKenzie \& O'Farrell, 1993)? Secondly, can developmental stability only be measured by fluctuating asymmetry or also by other asymmetrical patterns (McKenzie \& Clarke, 1988; Leary \& Allendorf, 1989; Palmer \& Strobeck, 1992; Graham et al., 1993a; McKenzie \& O'Farrell, 1993)? Finally, will general or specific environmental stresses influence asymmetry levels and patterns in different ways (Parsons, 1961, 1990; Graham et al., 1993b)? An analysis of the asymmetry phenotype of dieldrin- 
resistance genotypes of the Australian sheep blowfly, Lucilia cuprina, after development under different environmental conditions, allows an investigation of these questions.

The cyclodiene insecticide dieldrin was introduced to control L. cuprina in 1955 . By 1957 resistance was widespread, controlled by allelic substitution at the $R d l$ locus on chromosome V (McKenzie, 1987). Dieldrinresistant phenotypes have elevated asymmetry levels relative to susceptibles; the effect is dominant when flies develop under standard laboratory conditions (Clarke \& McKenzie, 1987; McKenzie et al., 1990).

Three key ecological stresses in the evolution of insecticide resistance in L. cuprina are larval density (Whitten et al., 1980), insecticide concentration (McKenzie \& Whitten, 1982) and developmental temperature (McKenzie, 1990, 1994). There is evidence that these variables influence developmental stability (Clarke \& Ridsdill-Smith, 1990; Clarke \& McKenzie, 1992). It is therefore possible to assess the effect of genotype and general or specific environmental stresses on the asymmetry phenotype by rearing known $R d l$ genotypes under conditions of different temperatures, larval densities and dieldrin concentrations. This paper reports such experiments and relates the results to the questions raised above.

\section{Materials and methods}

\section{Strains, crosses and measurements}

A standard wild-type strain (SWT) susceptible $(+/+)$ to dieldrin and a strain resistant to dieldrin $(R d l / R d l)$ were used. The resistant strain had been selected (Whitten et al., 1980) following mutation in SWT. Heterozygotes $(R d l /+)$ were produced by crossing these strains.

In each trial 10 flies of each genotype were scored for asymmetry in each environmental comparison. A total of 70 flies was scored for each genotype under each environmental condition by conducting seven trials with each genotype at intervals of one generation. Temperature, density and dieldrin concentration trials were conducted independently. Calculation of asymmetry values followed the methods of Clarke \& McKenzie (1987). The numbers of frontal head stripe, outer wing margin and $R_{4+5}$ wing vein bristles were counted on the left and right sides of the fly. Asymmetry for each fly was calculated as the absolute difference between left and right side scores pooled over the three characters. Equal weighting was given to each character. Asymmetry pattern was determined separately by the distribution of signed differences between left and right score (McKenzie \& Clarke, 1988).
Standard rearing conditions for $L$. cuprina are at $27^{\circ} \mathrm{C} \pm 1^{\circ} \mathrm{C}$ at a larval density of 100 per $140 \mathrm{~mL}$ of medium comprising meat meal mixed in water.

\section{Environmental variables}

Temperature One hundred first-instar larvae were placed in cups containing $140 \mathrm{~mL}$ of standard laboratory medium. The flies scored emerged after development at $20^{\circ} \mathrm{C}, 25^{\circ} \mathrm{C}, 27^{\circ} \mathrm{C}$ or $32^{\circ} \mathrm{C}, \pm 1^{\circ} \mathrm{C}$ in each case.

Density All experiments were conducted at $27 \pm 1^{\circ} \mathrm{C}$. Using first-instar larvae, densities of 25, 100, 200,300, 400 and 500 larvae per $140 \mathrm{~mL}$ of standard medium were established.

Dieldrin concentration The experiments were carried out at $27 \pm 1^{\circ} \mathrm{C}$ using 100 first-instar larvae on $140 \mathrm{~mL}$ of standard laboratory medium with concentrations of dieldrin chosen to induce insecticidedependent mortality in the range of $0-80$ per cent (Whitten et al., 1980; Davies et al., 1992). For $+/+$ genotypes the concentrations used were $0,0.0002$, $0.0003,0.0004,0.0005$ and 0.0006 per cent $(\mathrm{w} / \mathrm{v})$. $R d l /+$ genotypes developed on concentrations of 0 , $0.01,0.015,0.02,0.025$ and 0.03 per cent $(\mathrm{w} / \mathrm{v})$ whereas concentrations for $R d l / R d l$ were $0,0.04,0.07$, $0.1,0.125$ and 0.15 per cent $(w / v)$.

\section{Results}

\section{Temperature}

The data were analysed using a two-way analysis of variance. Developmental temperature does not significantly influence the asymmetry phenotype of $R d l / R d l$ $\left(F_{3,252}=0.11\right)$ or $R d l l+\left(F_{3,252}=0.02\right)$ but asymmetry values of $+1+$ increase at developmental temperatures above and below $27^{\circ} \mathrm{C}\left(F_{3,252}=2.64 ; P<0.05\right)$ (Fig. 1). Trial and interactive effects are not significant in any analysis. Susceptible phenotypes have lower mean asymmetry scores than $R d l / R d l$ and $R d l /+$ $\left(F_{2,756}=17.55 ; P<0.001\right)$ across the range of developmental temperatures. The latter two genotypes have comparable mean asymmetry values at each temperature (Fig. 1).

Increases in the mean asymmetry of $+/+$ as develepmental temperatures vary from $27^{\circ} \mathrm{C}$ result from increased fluctuating asymmetry (Palmer \& Strobeck, 1986). Signed left minus right differences remain unimodally distributed about zero for each character. The bimodal distributions about zero of these differences for $R d l / R d l$ and $R d l /+$ indicate antisymmetry (Palmer \& Strobeck, 1986) at each temperature for 


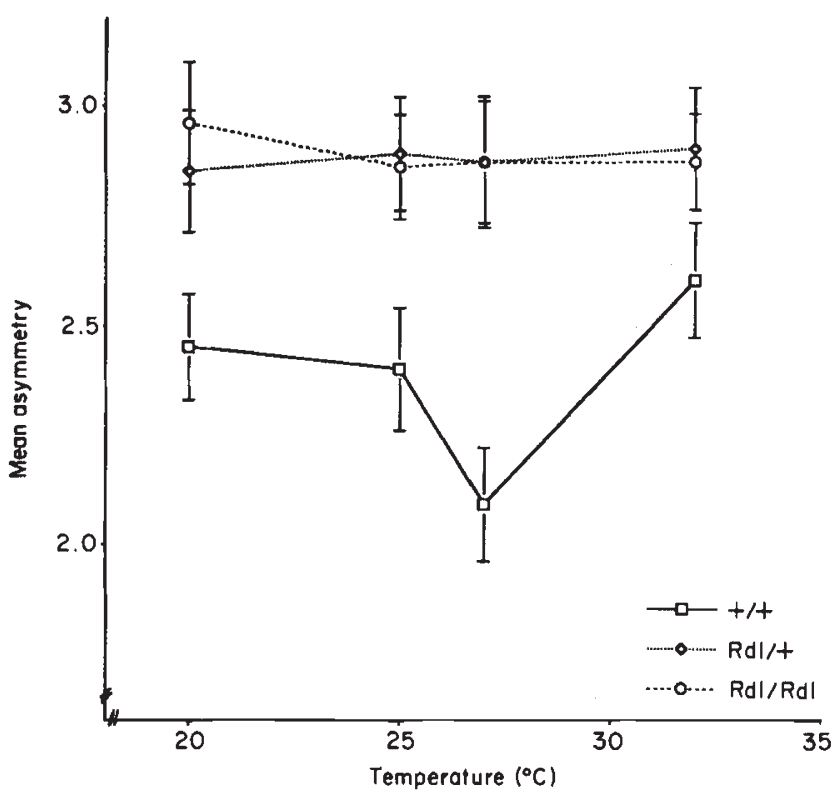

Fig. 1 Mean asymmetry \pm standard error of $+1+, R d l /+$ and $R d l / R d l$ Lucilia cuprina after development at $20^{\circ} \mathrm{C}$, $25^{\circ} \mathrm{C}, 27^{\circ} \mathrm{C}$ or $32^{\circ} \mathrm{C}$ at a density of 100 larvae per $140 \mathrm{~mL}$ of standard medium. Means are based on samples of 70 flies.

each character. Distributions for wing margin scores are typical of the patterns observed (Fig. 2).

\section{Density}

The analyses and results are similar to those observed for temperature. $R d l / R d l\left(F_{5,378}=0.41\right)$ and $R d l /+$ $\left(F_{5,378}=0.21\right)$ show density-independent mean asymmetries which are similar for each genotype at each density (Fig. 3). Trial and interactive effects were nonsignificant. $R d l / R d l$ and $R d l /+$ genotypes have significantly higher $\left(F_{2,1134}=17.65 ; P<0.001\right)$ mean asymmetry scores than $+/+$ which vary densitydependently, approaching the values of resistant phenotypes at extreme densities (Fig. 3). Similar asymmetry values are observed for $+/+$ at developmental densities of 25,300, 400 and 500 larvae per $140 \mathrm{~mL}$ of standard medium. Mean asymmetry at a larval density of 200 is intermediate between these values and the value at 100 larvae per $140 \mathrm{~mL}$. The effect is significant $\left(F_{5,378}=3.61 ; P<0.01\right)$ with insignificant trial and interactive effects.

Asymmetry patterns for the three genotypes followed those described for temperature (Fig. 2). For each character at each density fluctuating asymmetry occurred for $+/+$ while $R d l / R d l$ and $R d l \mid+$ consistently displayed antisymmetry.

\section{Dieldrin concentration}

For each genotype a positive association was observed between concentration of dieldrin and mean asymmetry (Fig. 4). In concentration ranges chosen to kill up to 80 per cent of each genotype, the percentage change in mean asymmetry between the highest and lowest value was greater for $+/+, 28$ per cent, than for $R d l / R d l$ and $R d l /+$, each 13 per cent. Fluctuating asymmetry was observed at each dieldrin concentration for $+\mid+$. Patterns for $R d l / R d l$ and $R d l \mid+$ were consistently antisymmetric.

\section{Discussion}

Previous studies have shown that when development occurs under standard laboratory conditions, $27^{\circ} \mathrm{C}$ and a larval density of 100 per $140 \mathrm{~mL}$ of standard medium, phenotypes of $L$. cuprina resistant to dieldrin, diazinon and malathion display increased asymmetry relative to susceptibles. The effect is dominant for dieldrin and diazinon resistance and partially dominant for malathion resistance (Clarke \& McKenzie, 1987; McKenzie et al., 1990; McKenzie \& O'Farrell, 1993; McKenzie \& Batterham, 1994).

Fluctuating asymmetry is observed for malathionresistant phenotypes, antisymmetry for phenotypes resistant to diazinon. A dominant modifier returns asymmetry values of resistant phenotypes to those of susceptibles; fluctuating asymmetry is observed for modified phenotypes. The modifier has no influence on dieldrin-resistant phenotypes (Clarke \& McKenzie, 1987; McKenzie \& Clarke, 1988; McKenzie \& O’Farrell, 1993).

Fluctuating asymmetry is accepted as a measure of developmental instability (Van Valen, 1962; Palmer \& Strobeck, 1986, 1992; Palmer et al., 1993; Markow, 1994). However, whereas some also support antisymmetry (Leary \& Allendorf, 1989; McKenzie \& Clarke, 1988; Graham, 1992; McKenzie \& O'Farrell, 1993) or directional asymmetry (Graham et al., 1993a,c) as measures of developmental instability, others do not (Palmer \& Strobeck, 1992; Palmer et al., 1993; Markow, 1994 for reviews). The present results for dieldrin-resistance phenotypes emphasize that asymmetry values depend on both genotype and environment, that fluctuating and antisymmetric patterns are equally predictive of developmental instability and that specific and general environmental stresses may produce different responses.

The influence of the $R d l$ allele in elevating asymmetry values above those of susceptibles is dominant (Figs 1 and 3 ). The asymmetry pattern changes from fluctuating for susceptibles $(+/+)$ to antisymmetric for resistants carrying the $R d l$ allele (Fig. 2). Develop- 
$+1+$

Rdl/ +

20
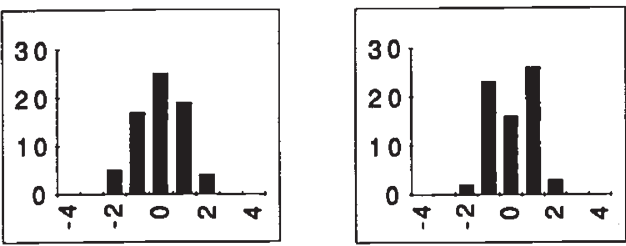

25

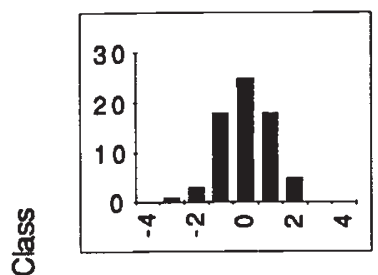

.5
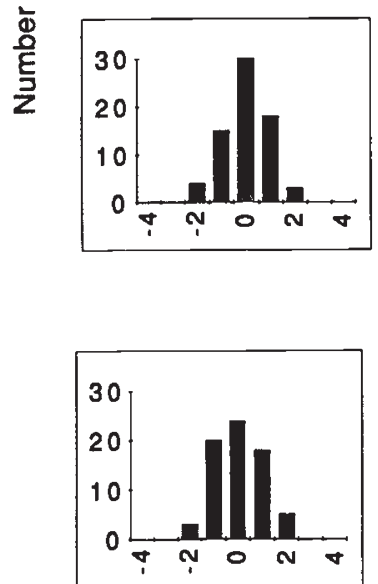

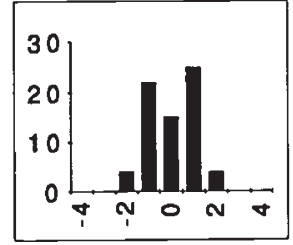

27

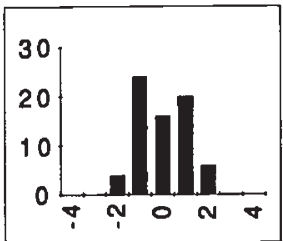

32

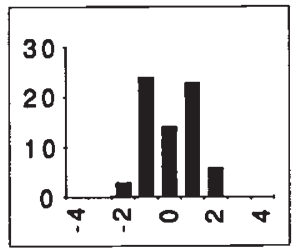

(L-R)
Rdl/Rdl
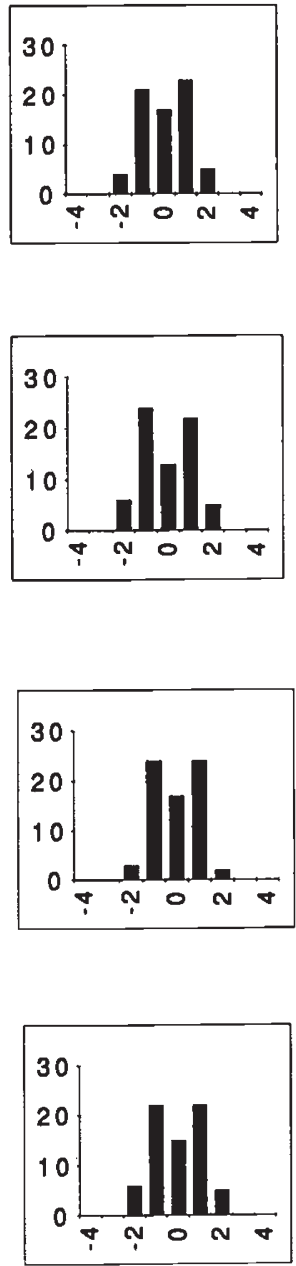

Fig. 2 Distribution of left minus right $(\mathrm{L}-\mathrm{R})$ differences in wing margin scores of $+1+, R d l /+$ and $R d l / R d l$ Lucilia cuprina after development at $20^{\circ} \mathrm{C}, 25^{\circ} \mathrm{C}, 27^{\circ} \mathrm{C}$ or $32^{\circ} \mathrm{C}$ at a density of 100 larvae per $140 \mathrm{~mL}$ of standard medium. Data are based on scores of 70 flies.

mental temperature and larval density do not affect asymmetry scores of resistant phenotypes but increased asymmetry is observed for susceptibles at temperatures and larval densities above and below standard conditions. Similar trends have been observed in other susceptible strains (Clarke \& McKenzie, 1992). Thus, general developmental stresses affect developmental stability of susceptible phenotypes but not of phenotypes resistant to dieldrin. The segregation of the $R d l$ allele defines a developmental threshold for these stresses. This genetically based threshold may be approached, but not exceeded, by environmental perturbation of developing susceptible phenotypes (Figs 1 and 3), a result in accord with general models of developmental constraint (Maynard
Smith et al., 1985; Parsons, 1990, 1992; Kieser, 1993). Therefore, genetically based changes may influence developmental stability, as measured by departures from symmetry.

Exposure of developing organisms to chemical stresses has produced different results. Increased fluctuating asymmetry has been observed when the grunion (Leuresthes tenuis) was exposed to DDT (Valentine \& Soule, 1973), the Australian bush fly (Musca vetustissima) to avermectin (Clarke \& RidsdillSmith, 1990) and Drosophila melanogaster to benzene (Graham et al., 1993c). Parsons (1961), however, found little evidence for an association between phenylthiourea concentration and fluctuating asymmetry in $D$. melanogaster and suggested depar- 


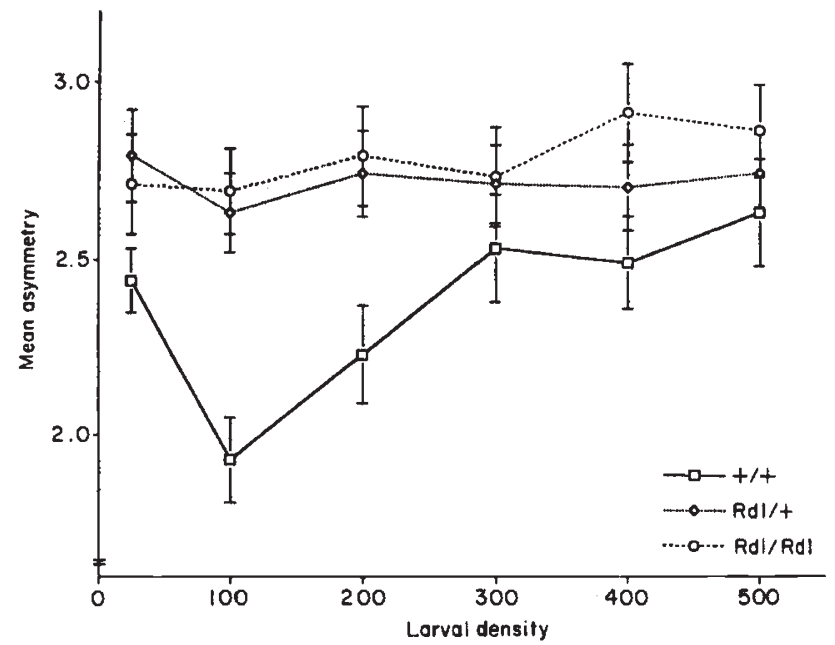

Fig. 3 Mean asymmetry \pm standard error of $+/+, R d l /+$ and $R d l / R d l$ Lucilia cuprina after development at $27^{\circ} \mathrm{C}$ at densities of 25, 100,200,300,400 and 500 larvae per 140 $\mathrm{mL}$ of standard medium. Means are based on samples of 70 flies. tures from symmetry may be more appropriately used to measure general rather than specific stresses.

In $L$. cuprina a positive correlation was observed between concentration of dieldrin and asymmetry for $R d l / R d l, R d l /+$ and $+/+$ (Fig. 4). The asymmetry phenotypes of the first two genotypes are antisymmetric, that of $+1+$ fluctuating. The results are thus supportive of a specific chemical stress influencing asymmetry (Valentine \& Soulé, 1973; Clarke \& Ridsdill-Smith, 1990; Graham et al., 1993c) but in this instance genotypes related to the stress are defined. Furthermore, it seems difficult to argue that, if changes in fluctuating asymmetry observed for susceptible phenotypes with increasing dieldrin concentration are indicative of developmental perturbation, the antisymmetric changes similarly observed for resistant phenotypes are not. Graham et al. (1993c), having observed a transition from fluctuating asymmetry to directional asymmetry in sternopleural bristle patterns
Fig. 4 Mean asymmetry \pm standard error of $+/+, R d l /+$ and $R d l / R d l$ Lucilia cuprina after development at $27^{\circ} \mathrm{C}$ at a density of 100 larvae per 140 $\mathrm{mL}$ of standard medium supplemented with dieldrin at the concentrations shown (per cent (w/v)). Means are based on samples of 70 flies.
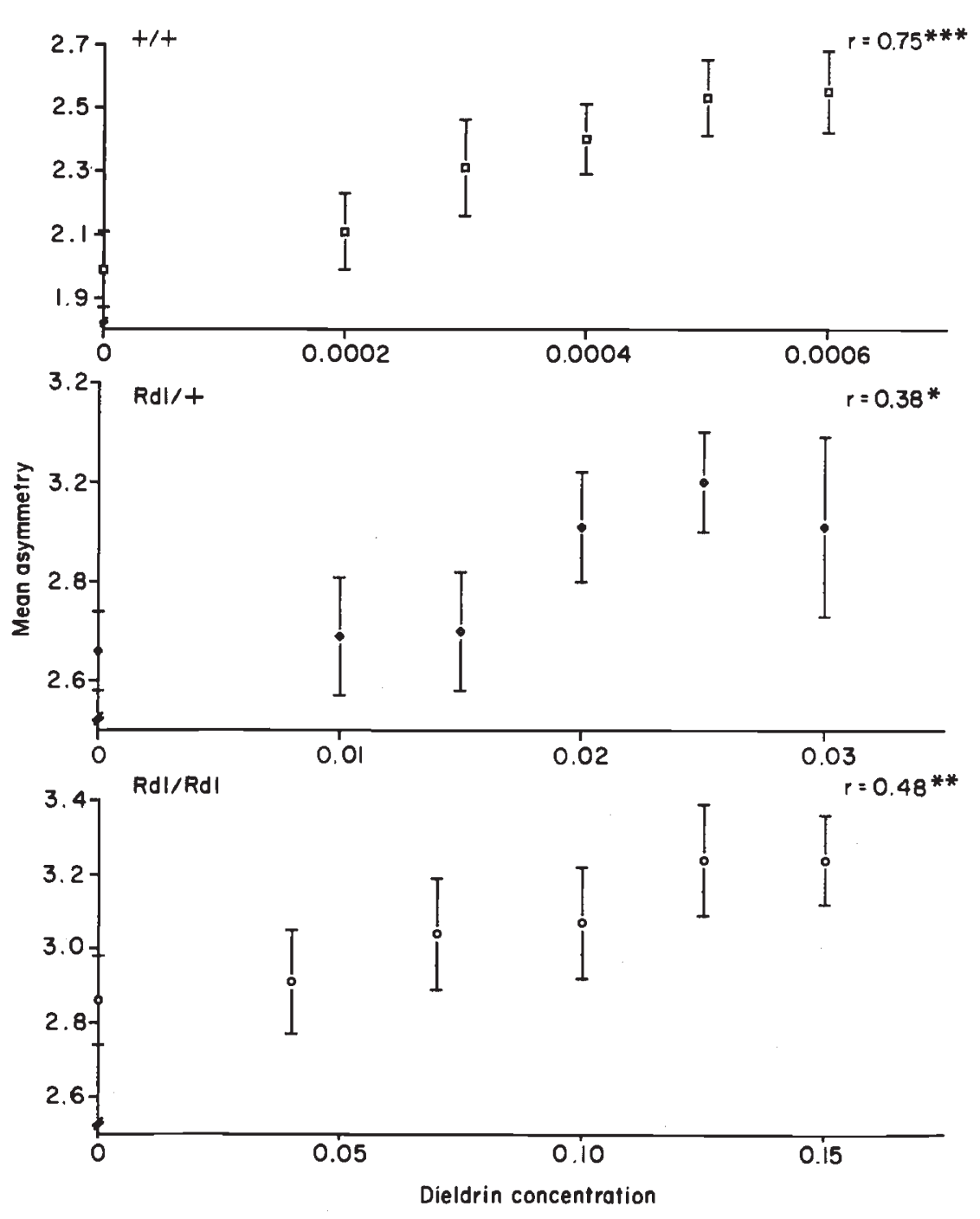
of $D$. melanogaster exposed to high levels of benzene, argued that patterns other than fluctuating asymmetry could be used to measure developmental perturbation. The present results with changing concentrations of dieldrin support this conclusion. However, if the genotypes were not defined the interpretation of the response to the general stresses of temperature and density would be difficult. For these stresses, susceptible phenotypes alone display environmental perturbation of development. The pattern is fluctuating asymmetry.

Thus, with respect to the issues raised in the Introduction, it is clear that, if departures from symmetry provide an estimate of developmental instability (Markow, 1994), patterns other than fluctuating asymmetry record developmental stress and that the influence of general and specific stresses is genotypically-dependent.

The comparison between resistant and susceptible phenotypes is essential to demonstrate that genotypic and environmental changes may influence the asymmetry phenotype. The asymmetry of dieldrinresistant phenotypes is unaffected by developmental temperature and larval density but is positively correlated with dieldrin concentration. Susceptible phenotypes are influenced by each environmental variable and their asymmetry increases with departure from normal developmental conditions.

These results indicate that the response to environmental stress during development is genetically dependent. The defined asymmetry threshold of resistant phenotypes to general environmental changes may be broken when a specific stress is related to a particular gene function. The distinction between general and specific stresses (Parsons, 1961, 1990, 1992; Hoffmann \& Parsons, 1991) is worthy of further experimentation. Of particular importance is to determine the mechanistic basis of developmental changes resulting in different patterns and levels of asymmetry. As the biochemical basis of insecticide resistance is frequently defined (McKenzie \& Batterham, 1994) resistance systems may provide the best opportunity. Analyses of diazinon and malathion resistance phenotypes of L. cuprina, where different patterns of asymmetry are observed and the biochemical basis of resistance is known (McKenzie \& Clarke, 1988; McKenzie \& O'Farrell, 1993; McKenzie \& Batterham, 1994), provide an excellent opportunity to do so.

Departures from symmetry have been used to monitor pollution and to answer questions of general evolutionary and developmental significance (Markow, 1994). The present results emphasize that in the absence of specific genotypic data extreme caution is necessary in an assessment of this phenotypic measure.

\section{Acknowledgements}

Phil Batterham and Kris Freebairn are thanked for helpful comments on the manuscript. Beverly Yen provided excellent technical assistance. Financial support was provided by the Australian Research Council and the Wool Research and Development Corporation.

\section{References}

ARTHUR, w. 1987. Theories of Life: Darwin, Mendel and Beyond. Penguin, Harmondsworth.

ATCHLEY, W. R. AND HALL, B. K. 1991. A model for development and evolution of complex morphological structures. Biol. Rev., 66, 101-157.

ClARKE, G. M. AND McKENZIE, J. A. 1987. Developmental stability of insecticide resistant phenotypes in blowfly; a result of canalizing natural selection. Nature, 325, 345-346.

CLARKE, G. M. AND McKENZIE, L. J. 1992. Fluctuating asymmetry as a quality control indicator for insect mass rearing processes. J. Econ. Entomol., 85, 2045-2050.

ClARKE, G. M., OLDROYD, B. P. AND HUNT, P. 1992. The genetic basis of developmental stability in Apis mellifera: heterozygosity versus genic balance. Evolution, 46, 753-762.

ClARKE, G. M. AND RIDSDILL-SMITH, T. J. 1990. The effect of avermectin $B_{1}$, on developmental stability in the bush fly, Musca vetustissima, as measured by fluctuating asymmetry. Entomologia exp. appl., 54, 265-269.

DAVIES, A. G., BATTERHAM, P. AND McKenZIE, J. A. 1992. Fatal association between dieldrin-resistant and susceptible Australian sheep blowflies, Lucilia cuprina. Proc. $R$. Soc. B., 247, 125-129.

GRAHAM, J. H. 1992. Genomic coadaptation and developmental stability in hybrid zones. Acta Zool. Fennica, 191, 121-131.

GRAHAM, J. H., FREEMAN, D. C. AND EMLEN, J. M. 1993a. Antisymmetry, directional asymmetry and dynamic morphogenesis. Genetica, 89, 121-137.

GRAHAM, J. H., FREEMAN, D. C. AND EMLEN, J. M. 1993b. Developmental stability: a sensitive indicator of populations under stress. In: Landis, W. G., Hughes, J. S. and Lewis, M. A. (eds) Environmental Toxicology and Risk Assessment, pp. 136-158. American Society for Testing and Materials, Philadelphia.

GRAHAM, J. H., ROE, K. E. AND WEST, T. B. 1993c. Effects of lead and benzene on the developmental stability of Drosophila melanogaster. Ecotoxicology, 2, 185-195.

HALL, B. K. 1992. Evolutionary Developmental Biology. Chapman and Hall, New York.

hOFFMANN, A. A. AND PARSONS, P. A. 1991. Evolutionary Genetics and Environmental Stress. Oxford University Press, Oxford.

KIESER, J. A. 1993. Evolution, developmental instability and the theory of acquisition. Genetica, 89, 219-225. 
LEARY, R. F. AND ALLENDORF, F. W. 1989. Fluctuating asymmetry as an indicator of stress: implications for conservation biology. Trends Ecol. Evol., 4, 214-217.

McKENZIE, J. A. 1987. Insecticide resistance in the Australian sheep blowfly - messages for pesticide usage. Chem. Ind., 8, 266-269.

McKENZIE, J. A. 1990. Selection at the dieldrin resistance locus in overwintering populations of Lucilia cuprina (Wiedemann). Aust. J. Zool., 38, 493-501.

McKENZIE, J. A. 1994. Selection at the diazinon resistance locus in overwintering populations of Lucilia cuprina (the Australian sheep blowfly). Heredity, 73, 57-64.

McKenZIE, J. A. AND BATTERHAM, P. 1994. The genetic, molecular and phenotypic consequences of selection for insecticide resistance. Trends Ecol. Evol., 9, 166-169.

McKENZIE, J. A. AND ClARKE, G. M. 1988. Diazinon resistance, fluctuating asymmetry and fitness in the Australian sheep blowfly, Lucilia cuprina. Genetics, 120, 213-220.

McKENZIE, J. A. AND O'FARRELL, K. 1993. Modification of developmental instability and fitness: malathion-resistance in the Australian sheep blowfly, Lucilia cuprina. Genetica, 89, 67-76.

McKENZIE, J. A. AND WHITTEN, M. J. 1982. Selection for insecticide resistance in the Australian sheep blowfly, Lucilia cuprina. Experientia, 38, 84-85.

McKENZIE, J. A., BATTERHAM, P. AND BAKER, L. 1990. Fitness and asymmetry modification as an evolutionary process. A study in the Australian sheep blowfly, Lucilia cuprina and Drosophila melanogaster. In: Barker, J. S. F., Starmer, W. T. and MacIntyre, R. J. (eds) Ecological and Evolutionary Genetics of Drosophila, pp. 57-73. Plenum Press, New York.

MARKow, T. A. (ed.) 1994. Developmental Instability: Its Origins and Evolutionary Implications. Kluwer Academic Publishers, Dordrecht.

MARKOW, T. A. AND RICKER, J. P. 1991. Developmental stability in hybrids between the sibling species pair, Drosophila melanogaster and Drosophila simulans. Genetica, 84, 115-121.

MAYNARD SMITH, J., BURIAN, R., KAUFFMAN, S., ALBERCH, P., CAMPBELL, J., GOODWIN, B., LANDE, R., RAUP, D. AND WOLPERT, L. 1985. Developmental constraints and evolution. Quart. Rev. Biol., 60, 266-287.
Møller, A. P. AND HOGLUND, J. 1992. Patterns of fluctuating asymmetry in avian feather ornaments: implications for models of sexual selection. Proc. R. Soc. B., 245, 1-5.

PALMER, A. R. AND STROBECK, C. 1986. Fluctuating asymmetry: measurement, analysis, patterns. Ann. Rev. Ecol. Syst., 17, 391-421.

PALMER, A. R. AND STROBECK, C. 1992. Fluctuating asymmetry as a measure of developmental stability: implications of non-normal distributions and the power of statistical tests. Acta Zool. Fennica, 191, 57-72.

PALMER, A. R., STROBECK, C. AND CHIPPINDALE, A. K. 1993. Bilateral variation and the evolutionary origin of macroscopic asymmetries. Genetica, 89, 201-218.

PARSONS, P. A. 1961. Fly size, emergence time and sternopleural chaeta number in Drosophila. Heredity, 16, 455-473.

PARSONS, P. A. 1990. Fluctuating asymmetry: an epigenetic measure of stress. Biol. Rev., 65, 131-145.

PARSONS, P. A. 1992. Fluctuating asymmetry: a biological monitor of environmental and genomic stress. Heredity, 68, 361-364.

SCHARLOo, w. 1991. Canalization: genetic and developmental aspects. Ann. Rev. Ecol. Syst., 22, 65-93.

THORNHILL, R. 1992. Fluctuating asymmetry, interspecific agression and male mating tactics of two species of Japanese scorpion flies. Behav. Ecol. Sociobiol., 30, 357-363.

VALENTINE, D. W. AND SOULE, M. E. 1973. Effects of $p, p^{1}$-DDT on developmental stability of pectoral fin rays in the grunion, Leuresthes tenuis. Fish. Bull., 71, 921-926.

VAN VALEN, L. 1962. A study of fluctuating asymmetry. Evolution, 16, 125-142.

WHITTEN, M. J., DEARN, J. M. AND McKenZIE, J. A. 1980. Field studies on insecticide resistance in the Australian sheep blowfly, Lucilia cuprina. Aust. J. Biol. Sci., 33, 725-735.

ZAKHAROV, v. M. 1992. Population phenogenetics: analysis of developmental stability in natural populations. Acta Zool. Fennica, 191, 7-30.

ZAKHAROV, v. M. AND GRAHAM, J. H. (eds). 1992. Developmental stability in natural populations. Acta Zool. Fennica, 191, 1-200. 